\title{
IN MEMORIAM: LESTER LUBORSKY
}

\author{
Horacio R. Losinno*
}

El 22 de Octubre de 2009, a los 89 años de edad, después de haber padecido una severa enfermedad de Alzheimer, murió Lester Luborsky.

Nació en Filadelfia, se graduó en la Central High School en 1938 y obtuvo su licenciatura en la Pennsylvania State University en 1942. Recibió su Ph.D. de la Universidad de Duke. Se formó como psicoanalista durante once años en la Fundación Menninger. Ha pasado la mayor parte de su carrera profesional en el Departamento de Psiquiatría de la Universidad de Pennsylvania, donde ejerció como docente desde 1968. Es autor de más de 400 publicaciones e intervino en una serie notable de proyectos que demuestran la validez de la investigación empírica en el campo del psicoanálisis.

Supo ganarse el afecto y el respeto de todos aquellos que tuvieron el honor de conocerlo personalmente por su generosidad y su exquisito sentido del humor. Consiguió, además, fundar y coordinar numerosos grupos de investigación en distintas partes del mundo.

Entre sus trabajos más relevantes se incluyen la Escala de Medición de Salud-Enfermedad (HSRS) y el Método del Tema Central de Conflicto en la Relación (CCRT). Este último supone una red singular de hipótesis, en la que se articulan exitosamente la metapsicología freudiana y la teoría de las relaciones objetales. Al emplearlo en mi Tesis de Doctorado pude apreciar, junto con su eficacia, la meritoria particularidad de permitir, apelando a una serie de procedimientos relativamente sencillos, la comparación de los patrones relacionales detectados en los diversos pacientes.

A Lester Luborsky, que dedicó su vida a la memorable tarea de fusionar el mundo de la psicoterapia con el de la investigación científica, le sobreviven un hijo, Peter; dos hijas, Ellen y Lise; cuatro nietos y tres bisnietos. Su esposa, Ruth, falleció en 2002.

*Doctor en Psicología. Docente Titular en la Universidad del Salvador y en la Universidad de Morón. 